\title{
Validation of a motion capture system for deriving accurate ground reaction forces without a force plate
}

\author{
Andrew C. Fry ${ }^{1 *}$, Trent J. Herda', Adam J. Sterczala ${ }^{1}$, Michael A. Cooper ${ }^{2}$ and Matthew J. Andre ${ }^{3}$
}

\author{
* Correspondence: acfry@ku.edu \\ 1 Osness Human Performance \\ Laboratories, University of Kansas, \\ 1301 Sunnyside Ave., 66045 \\ Lawrence, KS, USA \\ Full list of author information is \\ available at the end of the article
}

\begin{abstract}
Background: Human movement such as physical work, exercise and sport activities can be analyzed to determine kinetic (force) and kinematic (motion) characteristics. In the past, proper assessment of force variables requires force plates that can limit the types of activities performed. Additionally, large amounts of data are often generated, requiring often tedious and time-consuming analyses and calculations. Therefore, the purpose of this project was to compare the vertical ground reaction forces obtained from a force plate with calculated GRFs derived from a motion capture system during body weight squats for five healthy men.

Results: After performing three body weight squats, vertical ground reaction forces in Newtons were calculated for each data point for the force plate and motion capture system data, and synchronized from the point of peak force. There were no significant differences $(p<.05)$ for peak force, lowest force, or mean force between trials or modalities (force plate or motion capture system). Comparison of force-time curves with regression analyses indicated excellent agreement between testing modalities $\left(r=0.995, r^{2}=0.989\right.$, SEM $\left.=11.1 \mathrm{~N}\right)$.

Conclusions: These results indicate that ground reaction forces can be accurately derived from a motion capture system without the use of a force plate. Additionally, the large volumes of raw data were easily and rapidly analyzed using the easily customized software program. These results indicate that intricate kinetic characteristics of human motion can be validly determined without being restricted to performing on a force plate.
\end{abstract}

Keywords: Kinetics, Kinematics, Kinesiology, Squat

\section{Background}

For centuries, man has been intrigued by the complexities of human locomotion and movement. Over 300 years ago Borelli published an amazingly detailed description of various activities involving animal motion, but was limited by the technology available [1]. In the late $19^{\text {th }}$ century, Muybridge advanced the field of movement analysis when he used emerging photographic technology to document animal movement patterns [2]. Around the same time, Marey [3] developed then-advanced techniques for creating time-series photographic records of movement patterns called chronophotography. Marey's analyses also made it obvious to him that his kinematic data only told part of

(c) 2016 The Author(s). Open Access This article is distributed under the terms of the Creative Commons Attribution 4.0 International License (http://creativecommons.org/licenses/by/4.0/), which permits unrestricted use, distribution, and reproduction in any medium, provided you give appropriate credit to the original author(s) and the source, provide a link to the Creative Commons license, and indicate if changes were made. The Creative Commons Public Domain Dedication waiver (http://creativecommons.org/ publicdomain/zero/1.0/) applies to the data made available in this article, unless otherwise stated. 
the story, and he developed the traction dynamograph (now known as a load cell) and the dynamographic platform (now known as a force plate).

Advances were made in the $20^{\text {th }}$ century as the modern force plate was developed [4]. At the same time, cinematography technology was progressing along with an understanding of how to best use it to study human movement [5]. In addition, the use of multiple cameras for 3-dimensional analyses became possible with the development of synchronizing methods [6]. Eventually video techniques were developed which greatly facilitated data collection and analyses [7]. This was soon followed by the creation of a computer-interfaced charged-coupled device that could detect markers placed on the body [8], and eventually light-emitting diodes that signaled position data [9].

As both kinetic and kinematic analysis capabilities improved, it became readily apparent that the combination of body position data and the resulting ground reaction forces (GRF) were critical for a complete understanding of the biomechanics of human activity [10]. Although complex and tedious, the merging of these variables is possible when data collection is properly performed [11]. Perhaps one of the most critical developments was the creation of direct linear transformation methods to convert video records to computerized data [12].

With the increasing rate of technology development, the limitations of needing to use a force plate for motion analysis are apparent. Many activities cannot be performed on a small force plate, while others need to be measured in the field. There is concern over the inability to collect valid GRF data without a force plate, and the lack of userfriendly software to facilitate analyses [13]. Moreover, although inverse dynamics can be used to determine kinetic data for specific joints and body segments, there is a need for appropriate technology and software that can accurately and easily derive these large data sets [14]. Recently, such a technology has been developed [15], and it is the purpose of this study to examine the validity of this system to accurately determine GRFs during human exercise without the use of a force plate. Combined with an accurate motion capture system (MCS), this technology would ultimately permit the substantial and complex calculations of individual joint torques and segmental forces to be determined without being constrained to the space of a force plate.

\section{Results}

Mean \pm SD values for peak force, lowest force and mean force for each measurement system and trial are reported in Table 1 . There were no significant two-way interactions $(P=$ $0.462, P=0.684, P=0.551)$ or main effects for condition $(P=0.759, P=0.711, P=0.667)$ or trial $(P=0.107, P=0.828, P=0.094)$ for ground reaction peak force, lowest force and mean force, respectively. For the regression analysis on the average force plate and MCS values, the $R, R^{2}$, and SEM values were 0.995, 0.989, and $11.1 \mathrm{~N}$, respectively. Figure 1 illustrates the resulting force-time curves for the concentric phase of the body weight squat as determined from both the force plate and the MCS.

\section{Discussion}

The major finding of the present study is that the MCS described by Moodie [15] resulted in consistently accurate GRFs for the concentric phase of a body weight squat. Not only was the squatting task very repeatable, but both the force plate and the MCSderived data were similar. The precision of the derived GRFs is reflected in the SEM of only $11.1 \mathrm{~N}$. In order to statistically compare the resulting force-time curves for both 
Table 1 Comparison of forces measured by force plate and motion capture system. Kinetic data $(\mathrm{X} \pm \mathrm{SD})$ for the concentric phase of body weight squats as measured directly from a force plate or as derived from a motion capture system. No significant differences were observed between any trials or between measurement systems ( $p>0.05)$

\begin{tabular}{llcc}
\hline Variable & Trial & Force plate & Motion capture system \\
\hline Peak Force $(\mathrm{N})$ & 1 & $1210.4 \pm 280.2$ & $1206.3 \pm 288.7$ \\
& 2 & $1205.1 \pm 278.9$ & $1189.2 \pm 260.9$ \\
Lowest Force $(\mathrm{N})$ & 3 & $1216.7 \pm 310.3$ & $1219.4 \pm 328.4$ \\
& 1 & $745.8 \pm 107.9$ & $739.8 \pm 92.9$ \\
Mean Force $(\mathrm{N})$ & 2 & $736.3 \pm 98.2$ & $738.5 \pm 103.9$ \\
& 3 & $712.9 \pm 86.7$ & $713.6 \pm 83.4$ \\
& 1 & $923.3 \pm 150.9$ & $931.1 \pm 154.2$ \\
& 2 & $932.9 \pm 153.1$ & $931.6 \pm 147.0$ \\
\hline
\end{tabular}

measuring systems, regression analysis was used, resulting in an $R^{2}=0.989$. This type of analysis permitted comparison of the actual mean force-time curves for each testing modality.

Although force plates are often the testing device of choice for determining GRF, numerous other devices has been developed to access kinetic data for human performance. Small force sensors worn like a shoe have produced acceptable GRF data, and although somewhat bulky, appear to be appropriate for assessing gait [16]. On the other hand, when similar devices have been used to assess tasks such as lifting, greater error resulted, suggesting these types of devices may not be appropriate for other forms of activity [17]. Other research has examined force sensors inserted in the shoe. These devices have produced valid data when testing GRF during various types of gait [18, 19]. Another approach to assessing GRF during gait successfully used force sensors embedded under the running surface of a treadmill [20]. Regardless of the type of activity performed, the resonant frequency of the force plates used must be appropriate for the

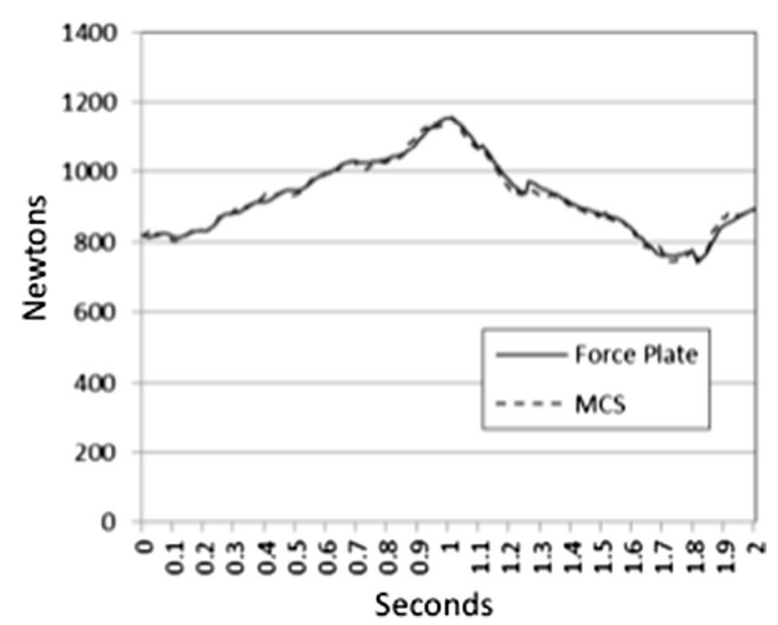

Fig. 1 Comparison of the force-time curves for the concentric phase of a body weight squat for either a force plate or a motion capture system (MCS) 
type of activity being analyzed [21]. Recently, a tri-axial force sensor has been developed that favorably compares with force plate and optical motion capture system data [22]. Alternatively, multiple force plates have been synchronized to create increased testing areas, thus permitting more types of activities to be monitored [23]. It is clear that numerous attempts have been made to develop force-sensing devices that improve human kinetics testing.

For many analyses, segmental and joint positions are required [10]. For these purposes, systems have been developed that combine GRF data with body orientation information [24], although results have been somewhat modest. When only kinematic data is used, double integration techniques have permitted determination of the system center of mass (COM) by calculating the segmental COM centroid [25]. While results have been favorable, this method requires use of segmental masses from reference data [26], thus limiting the precision for any one individual. Other attempts at using kinetic data to derive GRFs have had mixed results, possibly due to movement of markers on the surface of the skin [27].

When GRFs have been directly measured from a force plate, COM accelerations and displacements can be derived [28], although it has been noted that corresponding video data is required to obtain a more thorough understanding of the mechanics of the activity [10]. Regardless, the proper collection and use of GRF data for motion analyses has been nicely described by Miller [29]. The MCS used in the present study, along with the accompanying software for calculating the large amount of data generated, was user friendly, and more importantly, accurate and permitted determinations of complex calculations.

Though the MCS employed in the present investigation provides several advantages over traditional force plating testing, it is not without limitations. Accurate GRF measurement is dependent on a properly calibrated space, free of interfering obstacles. Additionally, accurate force measurement requires anatomically correct marker positioning and segmental mass determination via DXA. In comparison with force plate analysis, the MCS requires more complex and lengthy preparation. The MCS software provides rapid force calculations; therefore, the reduction in time associated with data analysis exceeds any additional time spent in preparation. The derivation of the estimated GRF requires a massive number of calculations from a large data set, and is greatly facilitated using this MCS software. Furthermore, the ability to measure force outside of the confines of a force plate seemingly outweighs the disadvantages associated with marker placement and DXA measures.

\section{Conclusions}

The use of the system employed in the present study negates the need for a force plate. Additionally, precise measures of each relevant body segment mass are available for each subject, thus contributing to the accuracy of the GRFs reported. The system used also permits relatively free movement in the measurement field as determined by how the sensors are arranged. As evident by the very small SEM of $11.1 \mathrm{~N}$, the result is an accurate and repeatable method to determine GRFs without the use of a force plate. 


\section{Methods}

\section{Purpose}

The purpose of this study was two-fold; to validate the ground reaction forces derived from a motion capture system with values determined directly from a force plate, and to determine if the accompanying software permitted ready access to the complex biomechanical calculations necessary. Subjects came to the laboratory and performed three trials of body weight squats on a force plate while simultaneously being recorded with a motion capture system. Force values calculated from the motion capture system were compared to values calculated from a force plate (independent variables). The dependent variables of peak force, lowest force, and mean force values were calculated and compared between the force plate and motion capture system. In addition, correlations of the synchronized force-time data points were performed between the force plate and motion capture system values for all trials.

\section{Subjects}

Five healthy men $(\mathrm{X} \pm \mathrm{SD}$; age $=21.0 \pm 4.3$ years; body mass $=92.9 \pm 15.3 \mathrm{~kg}$; height $=1.85 \pm$ $0.10 \mathrm{~m}$ ) volunteered for this investigation. Each subject completed a pre-exercise health status questionnaire and signed a written informed consent document before testing. Prior to any exercise testing, each subject was scanned with a DXA to determine segmental masses (GE Prodigy, Madison, WI). These data were then used for later analyses. None of the subjects reported any current or ongoing neuromuscular diseases or musculoskeletal injuries specific to the ankle, knee, or hip joints. This study was approved by the University's institutional review board for human subjects research.

\section{Procedures}

Subjects were required to perform 3 body weight squats separated by 30 s of rest. While on the uni-axial force plate (RoughDeck, Rice Lake Weighing Systems, Rice Lake, WI), the participants were instructed to perform a squat with a controlled velocity to a parallel depth and back to the starting position. Parallel was defined as the inguinal fold at the proximal end to the thigh being below the level of the superior border of the patella. Although the velocity was controlled, each subject self-selected the velocity during the movement. Participants used a shoulder width stance with feet flat on the ground during the squat movement. In addition, participants extended their arms forward during the movement, which allowed the arms to be parallel to the ground throughout the movement.

Prior to placement on the force plate, subjects put on a form fitting full body suite on which 43 markers were placed with Velcro (i.e., ankles, knees, hips, etc.) to form rigid bodies to track joint and segment positions (see Figs. 2 \& 3). All the experimental tests were performed with a customized motion capture system (MCS) using Optitrack Flex V100R2 hardware and Arena Motion Capture Software (Optitrack System, Natural Point, Inc., Corvallis, OR). The implemented acquisition system was composed of five infrared synchronized cameras that were mounted around the capture volume. Calibration procedures were performed prior to experimental testing in accordance to the Optitrack Flex V100R2 user guide (http://docplayer.net/7564823-Tracking-tools-2-4-0-user-s-guide.html), which included both dynamic and static calibrations. 


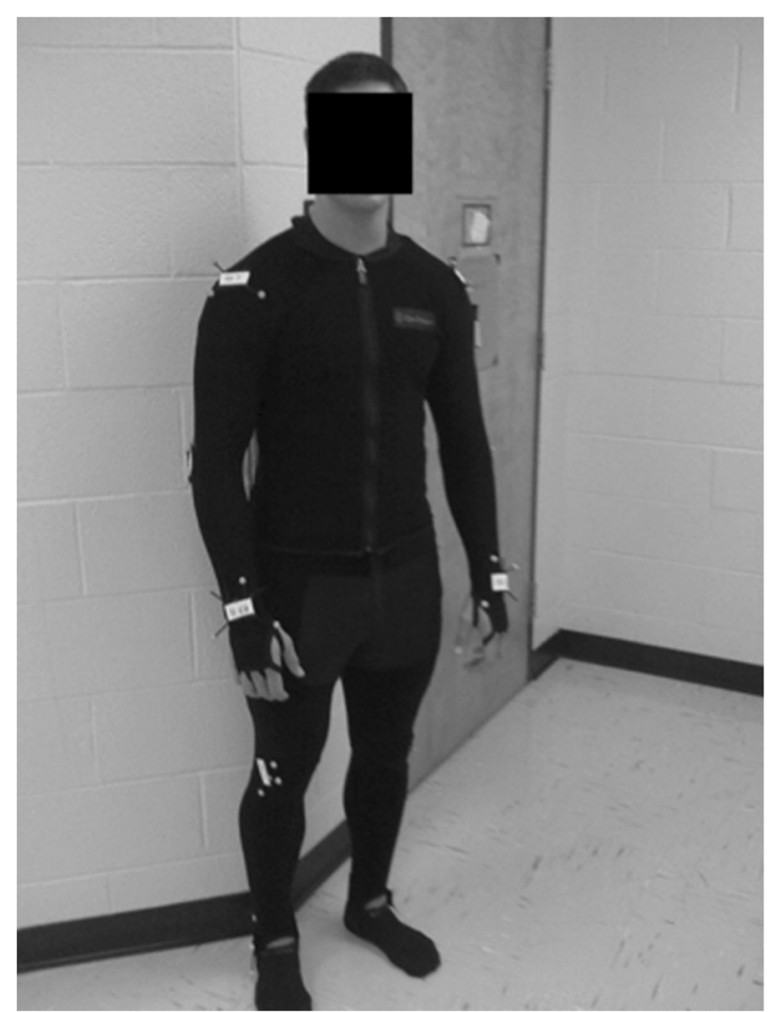

Fig. 2 Subject shown wearing the body suit with markers

The signal from the force plate was recorded with a Biopac data acquisition system (MP150WSW, Biopac Systems, Inc., Santa Barbara, CA) during each assessment. The force signal was sampled at $1000 \mathrm{~Hz}$ using a 16-bit analog-to-digital converter interfaced with a desktop computer. Since the MCS sampled at $100 \mathrm{~Hz}$, the force plate data's sampling rate was adjusted to $100 \mathrm{~Hz}$ offline (LabVIEW V 8.5, National Instruments Corp., Austin, TX) to match the MCS. GRFs (N) were calculated for each data point for the force plate and MCS data. Proprietary methods were used to calculate GRFs from the MCS data [15]. Ground reaction peak force (PF) and lowest ground reaction force (LF) were calculated as the highest and lowest 0.10 s epoch measured by the force plate and MCS,

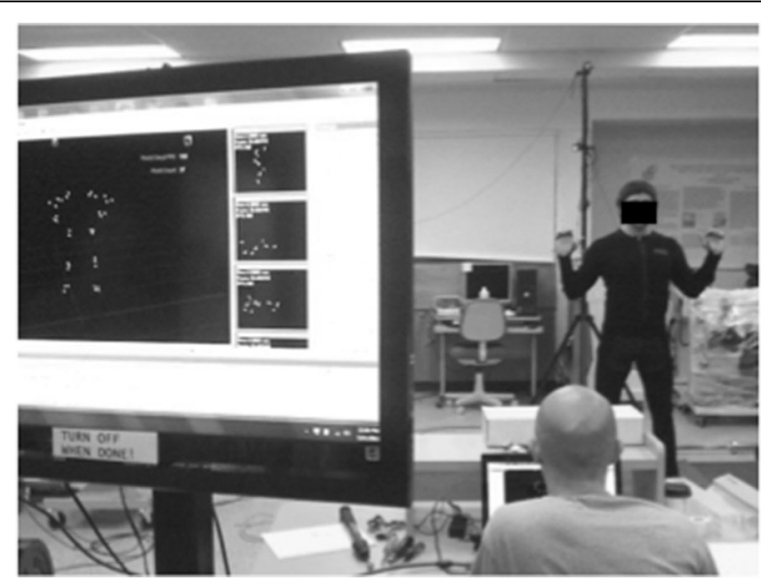

Fig. 3 Subject preparing to perform a body weight squat. Note the real-time kinematic figure on the screen at left 
respectively. The data point at which the peak force was observed was used to synchronize the signals from the MCS and the force plate. Specifically, the 100 data points (1 s) prior to PF and the 100 data points immediate after the PF as calculated by the two devices, were matched. The data point matching resulted in a synchronized two-second epoch, for which ground reaction mean force (MF) was calculated.

\section{Statistical analysis}

All data are reported as $\overline{\mathrm{X}} \pm \mathrm{SD}$. Linear regression was performed on the $2 \mathrm{~s}$ epoch of force plate and MCS values (collapsed across trials and subjects) with the Pearson correlation $(R)$, coefficient of determination $\left(R^{2}\right)$, and standard error of the measurement (SEM) calculated. For each data point in the two-second synchronized epoch, the GRF as calculated by the force plate was compared with the GRF calculated by the MCS. Three 2-way repeated measure ANOVAs (condition [force plate vs. MCS] vs. trial [1 vs. 2 vs. 3]) were used to examine differences between the force plate and MCS for PF, LF, and MF. Significance was set at $p<0.05$.

\section{Abbreviations}

COM: Center of mass; DXA: Dual-energy X-ray absorptiometry; GRF: Ground reaction force; Hz: Hertz; LF: Lowest ground reaction force; MCS: Motion capture system; MF: Ground reaction mean force; N: Newtons; PF: Ground reaction peak force; R: Pearson correlation; $R^{2}$ : Coefficient of determination; SEM: Standard error of measurement

\section{Acknowledgements}

The authors would like the thank Patrick Moodie, Ryan Moodie, Ryan Comeau and Derek Wassom of the Dynamic Athletics Research Institute, Lenexa, KS, for their gracious assistance. The authors would also like to acknowledge the assistance of Drs. Philip M. Gallagher and J. Phillip Vardiman during the process of data collection.

\section{Authors' contributions}

MJA assisted with data collection and manuscript preparation. MAC assisted with data collection and manuscript preparation. ACF conceived of the study, designed and coordinated the study and aided in manuscript preparation. TJH coordinated data collection, performed statistical analysis of data, and contributed to the discussion section of the manuscript. AJS assisted with manuscript preparation. All authors read approved the final manuscript.

\section{Authors' information}

ACF, TJH and AJS are members of the Research \& Coaching Performance Team at the University of Kansas, which regularly generates large amounts of biomechanical data to analyze and critique sport technique and performance.

\section{Competing interests}

The authors declare that they have no competing interests.

\section{Author details}

${ }^{1}$ Osness Human Performance Laboratories, University of Kansas, 1301 Sunnyside Ave., 66045 Lawrence, KS, USA.

${ }^{2}$ Department of Anatomy \& Cell Biology, University of Kansas Medical Center, Kansas City, KS 66160, USA. ${ }^{3}$ Department of Exercise and Sport Science, University of Wisconsin-La Crosse, La Crosse, WI 54601, USA.

Received: 3 September 2015 Accepted: 14 September 2016

Published online: 28 September 2016

\section{References}

1. Borelli GA. De Motu Animalium. Bernabo: Ex Typographia Angeli; 1680.

2. Muybridge E. Animal Locomotion: an Electrophotographic Investigation of Connective Phases of Animal Movements. Philadelphia: J.B. Lippincott Co.; 1887.

3. Marey EJ. Movement. New York: D. Appleton and Co.; 1895.

4. Cunningham DM, Brown GW. Two devices for measuring the forces acting on the human body during walking, Proceedings of the Society of Experimental Stress. 1952.

5. Plagenhoef S. Patterns of Human Motion. Englewood Cliffs: Prentice-Hall, Inc; 1971.

6. Blivernicht DL. Multi-dimensional timing device for cinematography. Res Q Exerc Sport. 1967;38(1):146-8.

7. Winter DA, Greenlaw RK, Hobson DA. Television-computer analysis of kinematics of human gait. Comput Biomed Res. 1972;5(5):498-504.

8. Brugger W, Milner M. Computer-aided tracking of body motions using a c.c.d.-image sensor. Med Biol Eng Comput. 1978;16(2):207-10.

9. Gowitzke BA, Milner M. Scientific Bases of Human Movement. 3rd ed. Baltimore: Williams \& Wilkins; 1988.

10. Cavanagh PR, Andrew GC, Kram R, Rodgers MM, Sanderson DJ, Henning EM. An approach to biomechanical profiling of elite distance runners. Int J Sport Biomechanics. 1985;1:36-62. 
11. Harman E. The measurement of human mechanical power. In: Maud PJ, Foster C, editors. Physiological Assessment of Human Fitness. 2nd ed. Champaign: Human Kinetics; 2006. p. 93-118.

12. Abdel-Aziz Yl, Karara HM. Direct linear transformation from comparator coordinates into object space coordinates in close-range photogrammetry. ASP Symposium on Close Range Photogrammetry. Falls Church: American Society of Photogrammetry; 1971.

13. Erdemir A, McLean S, Herzog W, van den Bogert AJ. Model-based estimation of muscle forces exerted during movements. Clin Biomech (Bristol, Avon). 2007;22(2):131-54. doi:10.1016/j.clinbiomech.2006.09.005.

14. Sarabon N. Development of software for comprehensive analyses of force plate measurements: technical note. Kinesiology. 2011;43(2):204-12.

15. Moodie P. Dynamic Athletics Research Institute, LLC, assignee. Apparatus and method for physical evalulation. U.S. patent 8527217. 2013.

16. Schepers HM, Koopman BFJM, van Asseldonk EH, Buurke JH, Veltink PH. Ambulatory estimation of ankle and foot dynamics and center of mass movement. Maastricht: Proceedings of Measuring Behavior; 2008.

17. Faber GS, Kingma I, Martin Schepers H, Veltink PH, van Dieen JH. Determination of joint moments with instrumented force shoes in a variety of tasks. J Biomech. 2010;43(14):2848-54. doi:10.1016/j.jbiomech.2010.06.005.

18. Forner-Cordero A, Koopman HJ, van der Helm FC. Inverse dynamics calculations during gait with restricted ground reaction force information from pressure insoles. Gait Posture. 2006;23(2):189-99. doi:10.1016/.gaitpost.2005.02.002.

19. Tillman MD, Fiolkowski P, Bauer JA, Reisinger KD. In-shoe plantar measurements during running on different surfaces: changes in temporal and kinetic parameters. Sports Engineering. 2002;5:121-8.

20. Verkerke GJ, Hof AL, Zijlstra W, Ament W, Rakhorst G. Determining the centre of pressure during walking and running using an instrumented treadmill. J Biomech. 2005;38(9):1881-5. doi:10.1016/j.jbiomech.2004.08.015.

21. Antonsson EK, Mann RW. The frequency content of gait. J Biomech. 1985;18(1):39-47.

22. Liu T. A wearable force plate system for the continuous measurement of triaxial ground reaction force in biomechanical applications. Measurement Science and Technology. 2010;21 (8). doi:10.1088/0957-0233/21/8/085804.

23. Wong AY, Sangeux M, Baker R. Calculation of joint moments following foot contact across two force plates. Gait Posture. 2010;31(2):292-3. doi:10.1016/i.gaitpost.2009.11.004.

24. Faber GS, Kingma I, van Dieen JH. Bottom-up estimation of joint moments during manual lifting using orientation sensors instead of position sensors. J Biomech. 2010;43(7):1432-6. doi:10.1016/j.jbiomech.2010.01.019.

25. Gutierrez-Farewik EM, Bartonek A, Saraste H. Comparison and evaluation of two common methods to measure center of mass displacement in three dimensions during gait. Hum Mov Sci. 2006;25(2):238-56. doi:10.1016/j. humov.2005.11.001.

26. Dempster WJ. Free body diagrams as an approach to the mechanics of human posture and motion. In: Evans FG, editor. Biomechanical Studies of the Musculo-Skeletal System. Springfield: Charles C. Thomas; 1961. p. 81-135.

27. Ren $L$, Jones RK, Howard D. Whole body inverse dynamics over a complete gait cycle based only on measured kinematics. J Biomech. 2008;41(12):2750-9. doi:10.1016/j.jbiomech.2008.06.001.

28. Cavagna GA, Saibene FP, Margaria R. External work in walking. J Appl Physiol. 1963;18:1-9.

29. Miller DI. Ground reaction forces in distance running. In: Cavanagh PR, editor. Biomechanics of Distance Running. Champaign: Human Kinetics; 1990. p. 203-24.

\section{Submit your next manuscript to BioMed Central and we will help you at every step:}

- We accept pre-submission inquiries

- Our selector tool helps you to find the most relevant journal

- We provide round the clock customer support

- Convenient online submission

- Thorough peer review

- Inclusion in PubMed and all major indexing services

- Maximum visibility for your research

Submit your manuscript at www.biomedcentral.com/submit 